MEDICAL GENETICS IN PRACTICE

\title{
New insights into cystinuria: 40 new mutations, genotype- phenotype correlation, and digenic inheritance causing partial phenotype
}

\author{
M Font-Llitjós*, M Jiménez-Vidal*, L Bisceglia*, M Di Perna, L de Sanctis, F Rousaud, L Zelante, \\ M Palacín, V Nunes
}

J Med Genet 2005;42:58-68. doi: 10.1136/jmg.2004.022244

See end of article for authors' affiliations

Correspondence to:

Dr Virginia Nunes, Centre de Genética Mèdica i Molecular (IRO-IDIBELL),

Hospital Duran i Reynals, Gran Via Km 2.7, s/n,

L'Hospitalet de Llobregat, Barcelona E-08907,

Spain; vnunes@iro.es

Received in revised form 3 September 2004 Accepted for publication 8 September 2004

* These authors contributed equally to the study

\begin{abstract}
Objective: To clarify the genotype-phenotype correlation and elucidate the role of digenic inheritance in cystinuria.

Methods: 164 probands from the International Cystinuria Consortium were screened for mutations in SLC3A7 (type A) and SLC7A9 (type B) and classified on the basis of urine excretion of cystine and dibasic amino acids by obligate heterozygotes into 37 type I (silent heterozygotes), 46 type non-I (hyperexcretor heterozygotes), 14 mixed, and 67 untyped probands.

Results: Mutations were identified in $97 \%$ of the probands, representing 282 alleles (86.8\%). Forty new mutations were identified: 24 in SLC3A1 and 16 in SLC7A9. Type A heterozygotes showed phenotype I, but mutation DupE5-E9 showed phenotype non-I in some heterozygotes. Type B heterozygotes showed phenotype non-I, with the exception of 10 type B mutations which showed phenotype I in some heterozygotes. Thus most type I probands carried type A mutations and all type non-l probands carried type $B$ mutations. Types B and A mutations contributed to mixed type, BB being the most representative genotype. Two mixed cystinuria families transmitted mutations in both genes: double compound heterozygotes (type AB) had greater aminoaciduria than single heterozygotes in their family.

Conclusions: Digenic inheritance is an exception (two of 164 families), with a limited contribution to the aminoaciduria values (partial phenotype) in cystinuria. Further mutational analysis could focus on one of the two genes (SLC3AI preferentially for type I and SLC7A9 for type non-I probands), while for mixed probands analysis of both genes might be required, with priority given to SLC7A9.
\end{abstract}

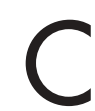
ystinuria is an autosomal inherited metabolic disorder characterised by impaired transport of cystine and dibasic amino acids in the proximal renal tubule and the gastrointestinal tract. A high cystine concentration in the urinary tract most often causes the formation of recurring renal cystine stones because of the low solubility of this amino acid. The overall estimated prevalence of the disease is $1 / 7000$ neonates, ranging from $1 / 2500$ neonates in Libyan Jews to $1 / 100000$ in the Swedish population. ${ }^{1}$

Cystinuria is classified into three types according to the urine phenotype in heterozygotes: type I (MIM220100), type non-I (MIM600918), and mixed. In type I cystinuria, heterozygotes have a normal pattern of amino acid excretion in the urine (phenotype I), which implies that the disease is transmitted by an autosomal recessive trait. In non-type I cystinuria, heterozygotes have a variable degree of hyperexcretion of cystine and dibasic amino acids (phenotype non-I), indicating that the disease is transmitted in a dominant mode with incomplete penetrance. ${ }^{2}$ Patients with mixed type cystinuria, who inherit phenotype I and non-I alleles from either parent, have also been described. ${ }^{3}$

Two genes responsible for cystinuria have been identified. Mutations in SLC $3 A 1$, located on chromosome 2pl6.3-21 and encoding the $\mathrm{b}^{0,+}$ transporter related protein rBAT, have up to now been shown to cause only type I cystinuria, ${ }^{4-7}$ and not type non-I. ${ }^{8}$ The gene causing type non-I cystinuria was assigned by linkage analysis to $19 \mathrm{q} 12-13.1,{ }^{9}{ }^{10}$ confined to a $1.3 \mathrm{Mb}$ region ${ }^{11}$ and identified as SLC7A9, ${ }^{2}$ the protein product of which $\left(\mathrm{b}^{\mathrm{o},+} \mathrm{AT}\right)$ heterodimerises with $\mathrm{rBAT}$ (SLC3A1) in kidney brush border membranes. ${ }^{12}$ The $\mathrm{rBAT} / \mathrm{b}^{0,+} \mathrm{AT}$ heteromeric complex is responsible for the $b^{0,+}$ amino acid transport system. This transporter belongs to the heteromeric amino acid transporter (HAT) family, which is formed by a heavy subunit (rBAT or $4 \mathrm{~F} 2 \mathrm{hc}$ ) linked by a disulphide bridge to a range of light subunits $\left(\mathrm{b}^{0,+} \mathrm{AT}\right.$ in the case of $\left.\mathrm{rBAT}\right){ }^{13} \mathrm{At}$ present, 79 SLC3AI and 50 SLC7A9 mutations-including nonsense, missense, splice site, and frameshift mutations and large rearrangements in both genes-have been described. ${ }^{1} 268$ 14-27

Despite the classification of the disease described above, we found that some SLC7A9 heterozygotes presented a urinary excretion phenotype near the control range, resembling SLC $3 A 1$ heterozygotes that are phenotypically silent. ${ }^{21}$ Since then, phenotype I heterozygotes carrying SLC7A9 mutations have been reported, and two SLC7A9 mutations (I44T and P261L) have been associated with this phenotype. ${ }^{24}{ }^{28}$ These findings make the existing cystinuria classification imprecise because type I cystinuria could be caused by mutations in SLC7A9 instead of SLC3A1. Consequently, a new scheme based only on genetic aspects has recently been proposed ${ }^{28}$ : type A, caused by two mutations in SLC3Al (rBAT); type B, caused by two mutations in SLC7A9 $\left(\mathrm{b}^{\mathrm{o},+} \mathrm{AT}\right)$; and the possibility of type $\mathrm{AB}$, with one mutation on each of the above genes (that is, cystinuria with digenic inheritance). However, it remains unclear whether type $A B$ implies a digenic inheritance of the disease. Given a similar frequency of mutations in SLC7A9 and SLC3AI, ${ }^{28}$ we would expect half

Abbreviations: DHPLC, denaturing high performance liquid chromatography; HAT, heteromeric amino acid transporter; RT-PCR, reverse transcriptase polymerase chain reaction; SSCP, single strand conformation polymorphism 
to be from $\mathrm{AB}$ disease. The prevalence of type $\mathrm{A}$ disease is similar to that of type $\mathrm{B}$ disease, but type $\mathrm{AB}$ is extremely rare. $^{28}$ Two explanations could account for this low prevalence. Type $\mathrm{AB}$ patients may have a mild phenotype and escape detection. Alternatively, these individuals may represent type B or type A disease with a coincidental mutation in the other subunit gene. In this case, type $\mathrm{AB}$ carriers might be obligate heterozygotes with the possibility of digenic inheritance causing some effects at the phenotypical level.

We focused our study on an exhaustive mutational analysis of a large cohort of patients with extensive genotype-phenotype correlations in order to clarify the cystinuria classification from a genetic point of view. Special emphasis was placed on SLC7A9 alleles that segregate as a silent phenotype in obligate heterozygotes, on mixed cystinuria families, and on possible digenic cases. Here we report the following: 40 new cystinuria specific mutations (24 in SLC3A1 and 16 in SLC7A9); 10 SLC7A9 mutations that associate with phenotype I in heterozygotes; the first SLC3AI mutation (dupE5-E9) that associates with phenotype non-I in heterozygotes; and two families with mixed cystinuria which carry mutations in both genes and whose amino acid excretion phenotype in urine indicates a contribution of digenic inheritance, described for the first time in cystinuria.

\section{METHODS}

\section{Patients: phenotypic and genetic classification}

The institutional review board of the participating centres approved the study and participants gave their informed consent.

Amino acid excretion was determined using morning urine samples or in a 24 hour collection, as described, ${ }^{29}$ and corrected per gram of creatinine excreted. All subjects who fulfilled the following criteria were included in the study:

- urine cystine excretion more than $1040 \mu \mathrm{mol} / \mathrm{g}$ creatinine in a single urine sample or in a 24 hour collection, and at least one identified cystine stone (emitted or surgically removed);

- siblings of cystinuria patients, defined above, with the same genetic mutations, even in the absence of stone identification.

We studied 164 independent patients and their relatives of the International Cystinuria Consortium (ICC) database. These probands were from Italy (91), Spain (50), Israel (12), Belgium (4), Portugal (3), Switzerland (2), England (1), and Germany (1). Information on genotype or phenotype for some of these patients is available elsewhere. ${ }^{2} 141520-2228$

For phenotype-genotype correlation studies two classifications were established, one based on urinary amino acid excretion and the other on the genetic findings.

\section{Classification based on urinary amino acid excretion}

Patients were classified as type I, type non-I, mixed, and untyped on the basis of the urinary excretion values of cystine and dibasic amino acids (lysine, arginine, and ornithine) by the obligate heterozygotes. Thus heterozygotes were considered phenotype non-I when at least two of the indices (cystine, lysine, arginine, ornithine, or the sum of cystine and the three dibasic amino acids in the urine) were above the 95th centile in controls; they were considered phenotype I when these indices were within the control range.

\section{Type 1}

Both parents showed a normal urine amino acid pattern (heterozygotes with excretion values within the control range-that is, phenotype I).

\section{Type non-I}

Urinary excretion of both parents was above controls (that is, phenotype non-I heterozygotes). In a few cases, the probands had a urinary amino acid profile similar to the parent transmitting the disease and within the upper range of the non-I heterozygote phenotype. In these cases, when the other parent showed a normal urinary excretion phenotype, the probands were considered to be heterozygotes with non-I cystinuria.

\section{Mixed}

Urinary excretion was above the control values in one of the parents (phenotype non-I) and normal in the other (phenotype I).

\section{Untyped}

Urinary excretion values for one or both parents were not available or were of doubtful classification (that is, inconsistent classification of members of the same family). ${ }^{21}$

Using these criteria, the 164 studied probands were classified as 37 type I, 46 type non-I, 14 mixed, and 67 untyped (table 1).

Table 1 Cystinuria type and genetic frequencies of the probands

\begin{tabular}{|c|c|c|c|c|c|c|c|}
\hline \multirow[b]{2}{*}{ Genotype } & \multicolumn{5}{|c|}{ Cystinuria type } & \multirow{2}{*}{\multicolumn{2}{|c|}{ Total probands (\%) }} \\
\hline & 1 & Non-I & Non-I carriers* & Mixed & Untyped & & \\
\hline $\begin{array}{l}\mathrm{AA} \\
\mathrm{AA}(\mathrm{B})\end{array}$ & $29 \dagger$ & & & $\begin{array}{l}2 \\
1\end{array}$ & $25+$ & $\begin{array}{l}56(34.1) \\
1(0.6)\end{array}$ & $126(76.8)$ \\
\hline$B B$ & 1 & $34 \ddagger$ & & 7 & $23+$ & $65(39.6)$ & \\
\hline $\mathrm{B}+$ & & & 3 & & & $3(1.8)$ & \\
\hline $\mathrm{BB}(\mathrm{A})$ & & & & 1 & & $1(0.6)$ & \\
\hline A? & 5 & & & 1 & 5 & $11(6.7)$ & $33(20.1)$ \\
\hline$B$ ? & 2 & 7 & & $2 \S$ & 11 & 22 (13.3) & \\
\hline$? ?$ & & 2 & & & 3 & $5(3.0)$ & \\
\hline Total probands (\%) & $37(22.6)$ & $43(26.2)$ & $3(1.8)$ & $14(8.5)$ & $67(40.9)$ & $164(100)$ & \\
\hline Total alleles & & & & 134 & & & \\
\hline Explained alleles (\%) & $67(90.5)$ & $78(87.6)$ & 25 (89.3) & $112(83.6)$ & & & \\
\hline
\end{tabular}

*Heterozygote probands with cystine lithiasis.

tIncludes one family with two mutations in the same chromosome in addition to the mutation found in the other chromosome.

flncludes two families with two mutations in the same chromosome in addition to the mutation found in the other chromosome.

$\S$ Includes two families with two mutations found in one chromosome and no mutation found in the other chromosome.

For patients $A A(B)$ and $B B(A)$, two alleles causing the disease and two explained alleles in each case have been taking into account in the calculations

A, allele SLC3A1 mutated; B, allele SLC7A9 mutated; +, normal allele; ?, unknown allele. 
Table 2 New SLC3A1 and SLC7A9 mutations

\begin{tabular}{|c|c|c|c|c|}
\hline Type & Nucleotide change & $\begin{array}{l}\text { Amino acid change/predicted } \\
\text { consequence }\end{array}$ & Exon or intron & Detection method \\
\hline \multicolumn{5}{|l|}{ SLC3A1 new mutations } \\
\hline \multirow[t]{16}{*}{ Missense } & c. $266 \mathrm{~T} \rightarrow \mathrm{C}$ & L89P & Exon 1 & SSCP \\
\hline & c. $368 \mathrm{~T} \rightarrow \mathrm{G}$ & M123R & Exon 1 & DHPLC \\
\hline & c. $371 \mathrm{~A} \rightarrow \mathrm{G}$ & Y124C & Exon 1 & DHPLC \\
\hline & c. $388 \mathrm{~T} \rightarrow \mathrm{C}$ & S130P & Exon 1 & DHPLC/SSCP \\
\hline & c. $410 \mathrm{~A} \rightarrow \mathrm{G}$ & D137G & Exon 1 & DHPLC \\
\hline & c. $446 \mathrm{~T} \rightarrow \mathrm{A}$ & L149Q & Exon 2 & DHPLC \\
\hline & c. $566 \mathrm{C} \rightarrow \mathrm{T}$ & T189M & Exon 2 & SSCP \\
\hline & c. $1043 \mathrm{~A} \rightarrow \mathrm{C}$ & H348P & Exon 6 & DHPLC \\
\hline & c. $1230 \mathrm{C} \rightarrow \mathrm{A}$ & N410K & Exon 7 & DHPLC \\
\hline & c. $1322 \mathrm{C} \rightarrow \mathrm{G}$ & P441R & Exon 7 & SSCP \\
\hline & c. $1364 \mathrm{C} \rightarrow \mathrm{T}$ & S455L & Exon 8 & DHPLC \\
\hline & c. $1366 C \rightarrow T$ & R456C & Exon 8 & DHPLC/SSCP \\
\hline & c. $1367 \mathrm{G} \rightarrow \mathrm{A}$ & $\mathrm{R} 456 \mathrm{H}$ & Exon 8 & SSCP \\
\hline & c. $1520 \mathrm{C} \rightarrow \mathrm{T}^{*}$ & S507L & Exon 9 & SSCP \\
\hline & c. $1702 \mathrm{G} \rightarrow \mathrm{A}$ & G568S & Exon 10 & DHPLC \\
\hline & c. $1998 \mathrm{C} \rightarrow \mathrm{G}$ & C666W & Exon 10 & DHPLC \\
\hline Nonsense & c. $1865 \mathrm{~T} \rightarrow \mathrm{G}^{*}$ & L622X & Exon 10 & SSCP \\
\hline Silent & c. $1035 \mathrm{G} \rightarrow \mathrm{A}$ & Aberrant splicingt & Exon 6 & SSCP \\
\hline Splice & c. $1012-23 C \rightarrow G$ & D338_Y378delfsX5 & Intron 5 & SSCP and RT-PCR \\
\hline \multirow[t]{3}{*}{ Frameshift } & c.664delT & $\mathrm{W} 222 \mathrm{f}_{\mathrm{s}} \times 3$ & Exon 3 & SSCP \\
\hline & c. 1221 dupT & P408fs X18 & Exon 7 & SSCP \\
\hline & c. 1699 1700delAG & $\mathrm{R} 567 \mathrm{fs} \times 8$ & Exon 10 & SSCP \\
\hline In frame deletion & c.1966_1968delCTT & L656del & Exon 10 & SSCP \\
\hline Large rearrangements & c.892_1332del & E298_M444del & Intron $4-7$ & PCR \\
\hline \multicolumn{5}{|l|}{ SLC7A9 new mutations } \\
\hline \multirow[t]{5}{*}{ Missense } & c. $184 G \rightarrow A$ & V62M & Exon 3 & DHPLC \\
\hline & c. $562 \mathrm{G} \rightarrow \mathrm{A}$ & V188M & Exon 5 & DHPLC \\
\hline & c. $695 \mathrm{~A} \rightarrow \mathrm{G}$ & Y232C & Exon 6 & SSCP \\
\hline & c. $847 \mathrm{C} \rightarrow \mathrm{T}$ & L283F & Exon 8 & DHPLC \\
\hline & c. $947 \mathrm{C} \rightarrow \mathrm{T}$ & $\mathrm{A} 316 \mathrm{~V}$ & Exon 9 & DHPLC \\
\hline Silent & c. $171 \mathrm{C} \rightarrow \mathrm{T}$ & Aberrant splicing $\ddagger$ & Exon 3 & SSCP \\
\hline \multirow[t]{6}{*}{ Splice } & c. $235+3+293$ del & L30fs X10 & Intron 3 & RT-PCR \\
\hline & c. $586 \mathrm{C} \rightarrow \mathrm{T}$ & L196_G202delfsX5 & Exon 5 & SSCP and RT-PCR \\
\hline & c. $604+2 \mathrm{~T} \rightarrow \mathrm{C}$ & L160X & Intron 5 & SSCP \\
\hline & c. $605-3 \mathrm{C} \rightarrow \mathrm{A}$ & $1203 f_{s} \times 27$ & Intron5 & DHPLC, SSCP \\
\hline & c. $1399+1 G \rightarrow T$ & $\mathrm{~K} 447 \mathrm{fs}_{\mathrm{s}} \times 22 \S$ & Intron 12 & DHPLC \\
\hline & c. $1400-3 C \rightarrow G$ & $\mathrm{~K} 447 \mathrm{fs}_{\mathrm{s}} \times 22 \S$ & Intron 12 & DHPLC \\
\hline \multirow[t]{2}{*}{ Frameshift } & c. 151 delT & S51fsX38 & Exon 3 & DHPLC \\
\hline & c. $1265 \_1266$ delTG & L424fs X62 & Exon 12 & DHPLC \\
\hline Large & c. $1224+4166 \_1399+119$ dup(4972) & $\mathrm{K} 386 f_{s} \times 78$ & Exon 12 & Multiplex \\
\hline rearrangements & c. $1224+4166 \_1399+119$ del(4972) & $\mathrm{V} 409 \mathrm{fs} \times 9$ & Exon 12 & Multiplex \\
\hline \multicolumn{5}{|c|}{$\begin{array}{l}\text { In addition to the } 40 \text { listed new mutations, a deletion of the } 3^{\prime} \text { end of } S L C 3 A 1 \text { has been identified in one chromosome of one patient, but the limits of this deletio } \\
\text { have not been studied. }\end{array}$} \\
\hline \multirow{2}{*}{\multicolumn{5}{|c|}{$\begin{array}{l}\text { When RT-PCR is indicated in the detection method, the effect of the } \\
\text { *These two mutations are located in the same chromosome. }\end{array}$}} \\
\hline \multirow{2}{*}{\multicolumn{5}{|c|}{$\begin{array}{l}\text { "These two mutations are located in the same chromosome. } \\
\text { tMutation eliminates an SF2/ASF exonic splicing enhancer motif. }\end{array}$}} \\
\hline & & & & \\
\hline \multicolumn{5}{|c|}{$\ddagger$ Mutation may create an alternative donor splice site 64 bp upstre } \\
\hline \multicolumn{5}{|c|}{$\begin{array}{l}\text { §The same protein product prediction but different genomic change. } \\
\text { bp, base pair; RT-PCR, reverse transcriptase polymerase chain reaction. }\end{array}$} \\
\hline
\end{tabular}

Classification based on the genetic findings

Patients were classified as type A, type B, type AB, and type ?? on the basis of the genetic findings.

\section{Type A}

Probands have mutations in SLC3Al (A? for one mutated allele identified and AA for two mutated alleles identified).

\section{Type B}

Probands have mutations in SLC7A9 (B? for one mutated allele identified and, $\mathrm{BB}$ and $\mathrm{B}+$ for two mutated alleles identified).

\section{Type $A B$}

Individuals have one mutation in SLC3A1 and one in SLC7A9. Probands with more than two mutated alleles were classified as $\mathrm{AA}(\mathrm{B})$ or $\mathrm{BB}(\mathrm{A})$, depending on the distribution of mutations in the two genes. ${ }^{28}$
Type ??

No mutations are found in the probands.

\section{Mutational analysis}

Probands and their relatives have been analysed for mutations in SLC3A1, SLC7A9, or in both genes. Mutations in this cohort of patients have been reported previously. ${ }^{2}{ }^{814} 20-22$ Genomic DNA or total RNA was isolated from peripheral blood lymphocytes following standard protocols. Patients with type I or type non-I cystinuria were initially screened for mutations in SLC3A1 and SLC7A9, respectively. Patients not fully genotyped were also analysed for the other cystinuria gene. Untyped patients were analysed for both genes as well. Mutational screening of the whole coding region, all intron/ exon boundaries, and some intron sequences (on average 50 base pairs (bp) on each side of the exons) was carried out by polymerase chain reaction (PCR), reverse transcriptase polymerase chain reaction (RT-PCR) (when RNA samples were available), single strand conformation polymorphism 
Table 3 Type of mutations distributed by allele in families with mixed cystinuria

\begin{tabular}{|c|c|c|c|}
\hline \multirow[b]{3}{*}{ Genotype } & \multirow[b]{3}{*}{ Families } & \multicolumn{2}{|l|}{ Alleles } \\
\hline & & \multirow{2}{*}{$\begin{array}{l}\text { Phenotype I } \\
\text { Explained }\end{array}$} & \multirow{2}{*}{$\begin{array}{l}\text { Phenotype non-I } \\
\text { Explained }\end{array}$} \\
\hline & & & \\
\hline AA & 2 & 2 & 2 \\
\hline $\mathrm{AA}(\mathrm{B})^{*}$ & 1 & 1 & 1 \\
\hline$B B$ & 7 & 7 & 7 \\
\hline $\mathrm{BB}(\mathrm{A}) \dagger$ & 1 & 1 & 1 \\
\hline A? & 1 & 1 & 0 \\
\hline $\mathrm{B}$ ? & 2 & 0 & 2 \\
\hline Total & $1 \overline{4}$ & 12 & 13 \\
\hline \multicolumn{4}{|c|}{$\begin{array}{l}\text { The urine phenotype of the obligate heterozygotes was used to classify the phenotype associated to each allele. } \\
\text { *The proband carries three mutations, two mutations A (one in each SLC } 3 A \text { l allele) and one mutation B in one of } \\
\text { the SLC7A9 alleles (see fig } 2 B \text { ). } \\
\text { †The proband carries three mutations, two mutations B (one in each SLC7A9 allele) and one mutation A in one of } \\
\text { the SLC3Al alleles (see fig } 2 A \text { ). }\end{array}$} \\
\hline
\end{tabular}

(SSCP), or Southern blot as described elsewhere, ${ }^{14}{ }^{21}$ and by denaturing high performance liquid chromatography (DHPLC) or semiquantitative multiplex PCR as described below. Direct sequencing was also carried out in all the individuals analysed to confirm the results obtained, to identify the mutated position in the gene, and to screen for mutations not detectable by these techniques. Southern blotting or semiquantitative multiplex PCR was used in patients with no mutations or only one mutation found with the other techniques, including direct sequencing. All the mutations described were checked on 100 control chromosomes to discard polymorphisms. Mutations listed or newly described here follow the nomenclature of the Human Genome Variation Society (www.genomic.unimelb.edu.au/ mdi/mutnomen/). All new mutations have been introduced in the HGMDB database (www.hgmd.org/).

\section{DHPLC analysis}

Samples for DHPLC analysis were amplified in a final reaction volume of $50 \mu \mathrm{l}$, using $100 \mathrm{ng}$ genomic DNA, 10× PCR buffer with $15 \mathrm{mM} \mathrm{MgCl}_{2}$ (Applied Biosystems, Foster City, California, USA), $200 \mu \mathrm{M}$ dNTPs, $0.30 \mu \mathrm{M}$ primer, and 1.5 units AmpliTaq Gold TM (Applied Biosystems). PCR cycling conditions consisted of an initial denaturation step at $95^{\circ} \mathrm{C}$ for 12 minutes followed by 35 cycles at $94^{\circ} \mathrm{C}$ for 30 seconds; the annealing temperature range was $55-57^{\circ} \mathrm{C}$ for 30 seconds, followed by $72^{\circ} \mathrm{C}$ for 30 seconds, and ending with a final elongation step at $72^{\circ} \mathrm{C}$ for eight minutes. DHPLC analysis was carried out on an automated DHPLC instrument (Transgenomic Inc, Santa Clara, California, USA).

Heteroduplex formation was induced by mixing an aliquot of unpurified PCR amplicon from patients and wild type sample in a $1: 1$ ratio. The mixed samples were heated to $95^{\circ} \mathrm{C}$ for five minutes and cooled slowly over 25 minutes to $35^{\circ} \mathrm{C}$. Usually, 7-10 $\mu \mathrm{l}$ of reannealed DNA duplexes were injected

\begin{tabular}{|c|c|c|}
\hline \multirow[b]{2}{*}{ Probands } & \multicolumn{2}{|l|}{ Alleles } \\
\hline & Type A & Type B \\
\hline AA & 112 & - \\
\hline$A A(B)^{*}$ & 2 & - \\
\hline BB & - & 130 \\
\hline B+ & - & 3 \\
\hline$B B(A)^{*}$ & - & 2 \\
\hline$A ?$ & 11 & - \\
\hline$B ?$ & - & 22 \\
\hline Total & 125 & 157 \\
\hline$\%$ of total alleles & 38.5 & 48.3 \\
\hline$\%$ of identified alleles & 44.3 & 55.7 \\
\hline
\end{tabular}

onto the column and then run at predetermined temperatures on the WAVE ${ }^{\circledR}$ system. The resolution temperature $(\mathrm{Tr})$ for each of the 12 PCR amplicons of genomic DNA from SLC3A1 and 13 from SLC7A9 analysed was predicted by using WaveMaker software (Transgenomic). The primers used for PCR amplification and DHPLC conditions are reported in table 1s in Supplementary Material, available online at the JMG website (www.jmg.com/supplemental). Fragments that showed variation in retention time or chromatogram shape from that of an unaffected control amplicon were then sequenced following the Big Dye Terminator protocol (PEABI, Foster City, California, USA) and analysed on an ABI 3100 DNA sequencer (Applied Biosystems).

\section{Semiquantitative multiplex PCR analysis in SLC7A9}

We undertook multiplex analysis for SLC7A9 in 13 patients from independent families in which no mutations or only one mutation had been found with the other techniques. This

\begin{tabular}{|c|c|c|c|c|c|c|}
\hline \multirow{3}{*}{ Probands } & \multicolumn{6}{|l|}{ Alleles } \\
\hline & \multicolumn{3}{|c|}{ Phenotype I } & \multicolumn{3}{|c|}{ Phenotype non-I } \\
\hline & Explained & Total & $\%$ & Explained & Total & $\%$ \\
\hline I & 67 & 74 & 90.5 & - & - & - \\
\hline non-I & - & - & - & 78 & 89 & 87.6 \\
\hline Mixed & 12 & 14 & 85.7 & 13 & 14 & 92.9 \\
\hline Total & 79 & 88 & 89.7 & 91 & 103 & 88.3 \\
\hline
\end{tabular}


Table 6 Urine excretion of cystine and dibasic amino acids in heterozygotes bearing the SLC3A1 mutation dupE5-E9

\begin{tabular}{|c|c|c|c|c|c|c|}
\hline \multirow[b]{2}{*}{ dupE5-E9 heterozygote } & \multirow[b]{2}{*}{ Phenotype } & \multicolumn{5}{|c|}{ Urine amino acid concentrations ( $\mu \mathrm{mol} / \mathrm{g}$ creatinine) } \\
\hline & & Cystine & Lysine & Arginine & Ornithine & Sum \\
\hline $\mathrm{F} 14-\mathrm{C} 119$ & non-I & 57 & 481 & $318^{*}$ & $94^{*}$ & $950^{*}$ \\
\hline F77-SR & non-I & $218^{*}$ & $1090^{*}$ & 33 & 30 & $1371^{*}$ \\
\hline F79-A145 & non-I & $167^{*}$ & $1595^{*}$ & 43 & $100^{*}$ & $1905^{*}$ \\
\hline F79-Al48 & non-I & $998 *$ & $1762^{*}$ & 12 & $133^{*}$ & $2905^{*}$ \\
\hline F106-D18 & 1 & 53 & 150 & $<1$ & $<1$ & 253 \\
\hline F106-D20 & untyped & NA & 345 & $<1$ & 35 & - \\
\hline $\begin{array}{l}\text { Type A heterozygote }(\mathrm{n}) \dagger \\
\text { [5th, 95th centile] }\end{array}$ & & $\begin{array}{l}70(7) \\
{[21,160]}\end{array}$ & $\begin{array}{l}171(18) \\
{[28,359]}\end{array}$ & $\begin{array}{l}24(4) \\
{[0,51]}\end{array}$ & $\begin{array}{l}26(4) \\
{[5,62]}\end{array}$ & $\begin{array}{l}300(23) \\
{[100,555]}\end{array}$ \\
\hline$(+/+)(n) t$ & Control (83) & $52(3)$ & $181(16)$ & $17(3)$ & $28(3)$ & $277(19)$ \\
\hline [5th, 95th centile] & & {$[23,109]$} & {$[35,499]$} & {$[0,48]$} & {$[7,70]$} & {$[93,620]$} \\
\hline \multicolumn{7}{|c|}{$\begin{array}{l}\text { Type A heterozygotes are those carrying mutations in SLC3A1 other than dupE5-E9. Controls are members of the fully genotyped ICC cystinuria families not } \\
\text { carrying the identified type A or type B mutations. } \\
\text { *Values above the } 95 \text { th centile in controls. } \\
\text { tThese values (mean (SEM)) have been reported previously. }{ }^{29} \\
\mathrm{~F} \text {, family; n, number of individuals; NA, not analysed; }<1 \text {, below the level of detection. }\end{array}$} \\
\hline
\end{tabular}

method was used previously for the analysis of large rearrangements in SLC3A1. ${ }^{20}$ Primer pairs for each of the 13 exons of SLC7A9 were used (table $2 \mathrm{~s}$ in Supplementary Material). One primer of each pair was labelled with FAM fluorescence (Invitrogen, San Diego, California, USA). As an external double dose control, a primer pair amplifying exon 5 from DSCRI (Down syndrome critical region gene 1) in chromosome 21 was added, together with the other set of 13 primer pairs. In a final volume of $20 \mu \mathrm{l}$, we mixed $100 \mathrm{ng}$ DNA, $0.2 \mathrm{mM}$ dNTPs, $1.5 \mathrm{U}$ Taq (Roche Diagnostics, Mannheim, Germany), 0.01\% gelatine, PCR buffer with 1.5 $\mathrm{mM} \mathrm{MgCl} 2$, and a mix of primers. The reaction started with an initial denaturation of five minutes at $94^{\circ} \mathrm{C}$, followed by 23 cycles of $94^{\circ} \mathrm{C}$ for 25 seconds, $58^{\circ} \mathrm{C}$ for 25 seconds, and $72^{\circ} \mathrm{C}$ 25 seconds. A final extension of seven minutes at $72^{\circ} \mathrm{C}$ was used. The PCR products were loaded on a 48 -well acrylamide gel together with an external fluorescent size standard (TAMRA-Gs500) and run in an ABI PRISM 377 DNA sequencer (Applied Biosystems). The results were processed by GENESCAN ${ }^{\mathrm{TM}}$ software (fig ls in Supplementary Material). To confirm the duplication of exon 12 in family 73 , we amplified a 518 bp fragment (only in the carriers) with 5 pmol of primers Fll (5'-ATGATTGAAATTGGAGGAGGG$\left.3^{\prime}\right)$ and Rlod (5' - CCTAATAAGCAGTCTACAAGA-3'), following standard methods, for 36 cycles of $94^{\circ} \mathrm{C} 30$ seconds, $58^{\circ} \mathrm{C} 30$ seconds, $74^{\circ} \mathrm{C} 30$ seconds, plus five minutes at $74^{\circ} \mathrm{C}$. To confirm the deletion in family 94, we amplified a 251 bp fragment using 5 pmol of primer F13 (5'- CAGACCATACTGTAAAGGACC - $3^{\prime}$ ) and R13 (5'CGTGGGCATGTGTCCTCCT $-3^{\prime}$ ), following standard methods, for 36 cycles, 10 cycles of $94^{\circ} \mathrm{C} 30$ seconds, $60^{\circ} \mathrm{C} 30$ seconds, $74^{\circ} \mathrm{C} 30$ seconds, 26 cycles of $90^{\circ} \mathrm{C} 30$ seconds, $59^{\circ} \mathrm{C}$ 30 seconds, $74^{\circ} \mathrm{C} 30$ seconds, plus seven minutes at $74^{\circ} \mathrm{C}$.

\section{RESULTS \\ Identification of 40 new cystinuria specific mutations in SLC3A1 and SLC7A9}

Mutational analysis was carried out exhaustively in 164 families that transmit cystinuria and which are included in the ICC database. We identified 24 new mutations in SLC3AI and 16 in SLC7A9 (table 2). None of these mutations was identified in 100 control chromosomes tested (data not shown). They included five frameshift mutations (three in SLC3A1 and two in SLC7A9) and one nonsense mutation in SLC3A1 which produce early stop codons; seven splice mutations (one in SLC3A1 and six in SLC7A9); 22 changes that affect single amino acid residues ( 16 and five missense mutations in SLC3AI and SLC7A9, respectively, and one deletion of a single amino acid residue in $S L C 3 A 1$ ); two silent changes affecting the coding region of the gene (one in SLC3A1 and one in SLC7A9); and three large rearrangements (one in SLC3Al and two in SLC7A9).

The two large SLC7A9 rearrangements were detected in two patients by semiquantitative multiplex PCR analysis: a $5 \mathrm{~kb}$ deletion (c.1224+4166_c.1399+119del) and a $5 \mathrm{~kb}$ duplication (c.1224+4166_c.1399+119dup), both affecting exon 12, originated by the crossing over of two $195 \mathrm{bp}$ sequences which differ by one nucleotide and are separated by $4778 \mathrm{bp}$ (fig 2s in Supplementary Material). The abnormal multiplex exon pattern in these two patients is shown in fig $3 \mathrm{~s}$ in Supplementary Material. These two mutations were confirmed by PCR primers which specifically amplify the mutated allele in both cases (fig $2 \mathrm{~s}$ in Supplementary Material). The protein product expected from the $5 \mathrm{~kb}$ duplication would have a frameshift from residue K386 with the addition of 78 missense residues before the first stop codon (p.K386fsX78). The $5 \mathrm{~kb}$ deletion affects intron 11 and the first $100 \mathrm{bp}$ of the $175 \mathrm{bp}$ of exon 12, and most probably results in the skipping of exon 12 , because the donor splice site is deleted and there are no potential donor sites around. The protein product of this deletion would have a frameshift from residue V409, adding nine missense residues before the first stop codon (p.V409fsX9), and lacking the last transmembrane domains XI and XII. However, RNA was not available from these patients to confirm the predicted changes.

Two of the splice mutations were localised outside the splice consensus sequences, and were checked to produce aberrant splicing by RT-PCR:

- $586 \mathrm{C} \rightarrow \mathrm{T}$ in $S L C 7 A 9$ is a silent exonic mutation that creates alternative donor site $20 \mathrm{bp}$ upstream of the consensus donor site. The resultant RNA (r.585_604del) is expected to produce a frameshift from residue L196 of $\mathrm{b}^{0+} \mathrm{AT}$ (p.L196_G202delfsX5) (data not shown);

- c.1012-23C $\rightarrow \mathrm{G}$ in $S L C 3 A 1$ localises in intron 5 and produces the skipping of exon 6 (r.1012_1136del), which is expected to result in a frameshift from residue D338 of rBAT (p.D338_Y378delfsX5) (data not shown).

The rest of the new splice mutations affect the consensus donor or acceptor splice site sequences, thereby indicating aberrant splicing.

The two silent mutations located in exonic regions (that is, no amino acid change) are predicted to create splicing defects, but it was not possible to check this by RT-PCR: 
Table 7 Urine excretion of cystine and dibasic amino acids in heterozygotes carrying the type B mutations (SLC7A9) associated with phenotype I

\begin{tabular}{|c|c|c|c|c|c|c|c|}
\hline & \multirow[b]{2}{*}{ Phenotype } & \multirow[b]{2}{*}{$\mathbf{n}$} & \multicolumn{5}{|c|}{ Urine amino acid concentrations ( $\mu \mathrm{mol} / \mathrm{g}$ creatinine) } \\
\hline & & & Cystine & Lysine & Arginine & Ornithine & Sum \\
\hline \multicolumn{8}{|l|}{ Common mutations } \\
\hline \multirow[t]{2}{*}{$\mathrm{A} 182 \mathrm{~T} /+\dagger$} & I & 6 & $82(16)$ & $151(52)$ & $31(7)$ & $21(6)$ & $285(57)$ \\
\hline & Non-I & 5 & $373(135)^{*}$ & $1865(1022)^{*}$ & $151(60)^{*}$ & $138(50)^{*}$ & $2527(1090)^{*}$ \\
\hline \multirow[t]{2}{*}{ T123M/+ } & & 2 & $29,229^{*}$ & 271,140 & 8,25 & 19,10 & 327,404 \\
\hline & Non-I & 2 & NA & $2596^{*}, 734^{*}$ & 42,17 & $176^{*}, 53$ & NA \\
\hline \multirow[t]{2}{*}{ V170M/+ } & I & 4 & $112(16)^{*}$ & $254(54)$ & $6(2)$ & $18(5)$ & $391(64)$ \\
\hline & Non-I & 12 & $441(87)^{*}$ & $1471(391)^{*}$ & $46(14)$ & $129(28)^{*}$ & $2087(475)^{\star}$ \\
\hline \multirow[t]{2}{*}{ c.614dupA/+‡ } & 1 & 1 & $260^{*}$ & 122 & 19 & 25 & 426 \\
\hline & Non-I & 18 & $607(95)^{*}$ & $2249(260)^{\star}$ & $90(14)^{*}$ & $220(31)^{*}$ & $3165(342)^{*}$ \\
\hline \multirow[t]{2}{*}{ G105R/+ } & I & 1 & 26 & 456 & 35 & 13 & 530 \\
\hline & Non-I & 31 & $524(75)^{*}$ & $1685(181)^{*}$ & $69(13)^{*}$ & $184(32)^{*}$ & $2461(249)^{*}$ \\
\hline R333W/+ & Non-1 & 19 & $634(139)^{*}$ & $2371(330)^{*}$ & $137(74)^{*}$ & $163(28)^{*}$ & $3304(482)^{*}$ \\
\hline \multicolumn{8}{|l|}{ Uncommon mutations } \\
\hline \multirow[t]{2}{*}{ G63R/+ } & & 2 & 60,59 & 330,322 & 11,14 & 41,38 & 442,433 \\
\hline & Non-I & 1 & $202^{*}$ & $504^{*}$ & 25 & & $750^{*}$ \\
\hline \multirow[t]{2}{*}{$\mathrm{A} 126 \mathrm{~T} /+$} & 1 & 1 & $140^{*}$ & 455 & ND & 8 & 603 \\
\hline & Non-I & 2 & $308^{*}, 338^{*}$ & $1144^{*}, 1373^{*}$ & $N D, 102^{*}$ & $0,237^{\star}$ & $1452^{*}, 2050^{*}$ \\
\hline \multirow[t]{2}{*}{ G195R/+ } & 1 & 1 & $116^{*}$ & 428 & ND & 19 & 563 \\
\hline & Non-1 & 1 & $439^{*}$ & $1948^{*}$ & $63^{*}$ & $247^{*}$ & $2697^{*}$ \\
\hline Y232C/+ & 1 & 1 & 108 & 125 & 11 & 42 & 286 \\
\hline W69X/+ & i & 1 & 51 & 249 & $55^{*}$ & 22 & 377 \\
\hline $\begin{array}{l}\text { Heterozygotes B+ } \\
{[5 \text { th, 95th centile] }}\end{array}$ & Non-I & 127 & $\begin{array}{l}534(37) \\
{[138,1348]}\end{array}$ & $\begin{array}{l}1930(113) \\
{[498,4492]}\end{array}$ & $\begin{array}{l}76(13) \\
{[0,337]}\end{array}$ & $\begin{array}{l}198(20) \\
{[21,522]}\end{array}$ & $\begin{array}{l}2758(154) \\
{[807,6081]}\end{array}$ \\
\hline
\end{tabular}

Values are mean (SEM) $\mu \mathrm{mol} / \mathrm{g}$ creatinine or individual values.

R333W is a common mutation with phenotype non-I in all the heterozygotes studied. Urine excretion of amino acids for heterozygotes with one mutated SLC7A9 allele $(B+)$ with phenotype non-l is also shown. Urine amino acid levels in controls are shown in table 6.

*Individual or mean values greater than 95th centile in controls (see table 6).

†A182T is not associated with mutation A354T in these alleles.

†c.614dupA is the present nomenclature for mutation c.800-801 insA.

NA, not analysed; ND, not detectable.

- c.171C $\rightarrow \mathrm{T}$ in SLC7A9 may create an alternative donor splice site 64 bp upstream of the consensus donor site;

- c. $1035 \mathrm{G} \rightarrow \mathrm{A}$ in $S L C 3 A 1$ localizes in a putative exonic splicing enhancer (ESE) for SF2/ASF with a score prediction of 2.36, while the mutation reduces the ESE prediction to 0.44 (that is, below threshold $=1.96$ ), suggesting aberrant splicing. ${ }^{30}$

In the ICC cohort of patients M467T is the most common SLC3A1 mutation, accounting for $26.4 \%$ of the total type A alleles, and together with T216M (6.4\%), DupE5-E9 (4.0\%), c.163delC (4.0\%), R270X (4.0\%), and c.765+lG $\rightarrow \mathrm{T}(3.2 \%)$ represents $48.0 \%$ of total type A alleles (table $3 \mathrm{~s}$ in

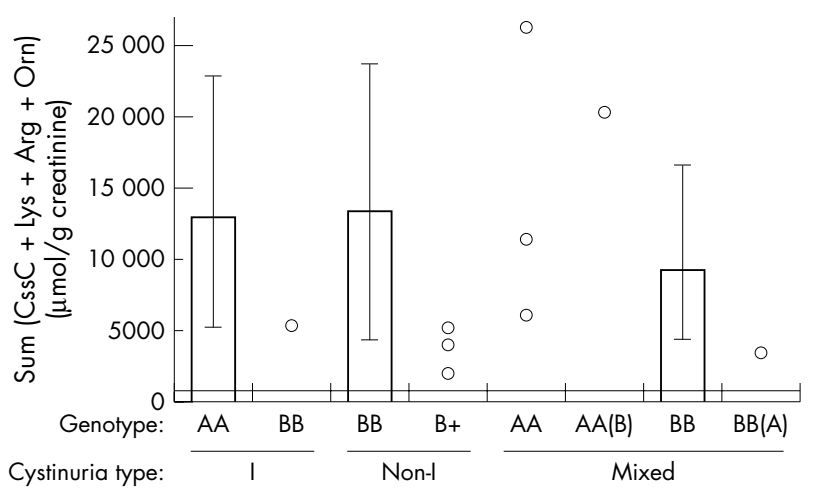

Figure 1 Sum of the urine of cystine and dibasic amino acids in patients with cystinuria classified by genotype and phenotype. Average (histograms) or individual data (dots), expressed as $\mu \mathrm{mol} / \mathrm{g}$ creatinine, correspond to the sum of the urine levels of cystine and dibasic amino acids shown in table 8 . Vertical lines represent the 5 th and 95th centile of the values of the corresponding group. Horizontal line $=95$ th centile in the control group (detailed in table 6).
Supplementary Material). For SLC7A9 the most common alleles are: G105R (27.4\%), R333W (12.1\%), V170M (11.5\%) (17 alleles in the Libyan-Jewish population and one in the Italian population), c.614dupA (the Human Genome Variation Society nomenclature for mutation c.80080linsA) $(7.0 \%)$ (eight alleles from Spain, two from Italy, and one from England), Al82T (5.1\%), T123M (3.8\%) and c.605-3C $\rightarrow$ A (2.5\%), which account for $69.4 \%$ of total type B alleles. Other SLC3A1 or SLC7A9 mutations were identified in three or fewer independent alleles.

The new mutations, together with those previously reported by the ICC (table $3 \mathrm{~s}$ in Supplementary Material) and by others, ${ }^{15-19}$ 23-27 make a total of 103 and 66 mutations identified in SLC3A1 and SLC7A9, respectively: 28 frameshift (14 in SLC3A1 and 14 in SLC7A9), seven nonsense (five in SLC3A1 and two in SLC7A9), 18 splice (seven in SLC3A1 and 11 in SLC7A9), 89 missense (59 in SLC3A1 and 30 in SLC7A9), two silent (one in $S L C 3 A 1$ and one in SLC7A9), five deletions or insertions of a single amino acid residue (one in $S L C 3 A$ I and four in SLC7A9), 18 large rearrangements (14 in SLC3AI and four in SLC7A9), and two cystinuria specific sequence variants in the promoter region of SLC3Al.

\section{Distribution of cystinuria alleles per phenotype and genotype}

The 164 cystinuria probands studied were classified on the basis of the urinary excretion of cystine and dibasic amino acids in obligate heterozygotes (urine phenotype) (see Methods) and also following the genetic classification proposed by Dello Strologo et al ${ }^{28}$ (type A, mutations in SLC3A1; type B, mutations in SLC7A9) (table 1). Potentially, these probands represent 325 cystinuria independent alleles (three probands were classified as non-I cystinuria heterozygotes, see below). In all, 282 alleles were characterised (that is, $86.8 \%$ ). Thus $13.2 \%$ of the potential alleles were not 
Table 8 Urine amino acid levels in patients classified by genotype and type of cystinuria

\begin{tabular}{|c|c|c|c|c|c|c|}
\hline \multirow[b]{2}{*}{ Genotype } & \multirow[b]{2}{*}{ Cystinuria type } & \multirow[b]{2}{*}{$\mathbf{n}$} & \multicolumn{4}{|c|}{ Urine amino acid concentrations ( $\mu \mathrm{mol} / \mathrm{g}$ creatinine) } \\
\hline & & & Cystine & Lysine & Arginine & Ornithine \\
\hline AA & 1 & 34 & $1655[647,3404]$ & $6577[2651,11635]$ & $3144[226,8373]$ & $1743[587,3441]$ \\
\hline AA & Mixed & 3 & $782,2117,5556$ & $3308,5715,11418$ & $1234,2817,7025$ & $718,1636,1918$ \\
\hline $\mathrm{AA}(\mathrm{B})$ & Mixed & $1 \dagger$ & 2569 & 9836 & 2952 & 5172 \\
\hline $\mathrm{BB}$ & I & 1 & 2692 & 2280 & 111 & 304 \\
\hline $\mathrm{BB}$ & Non-I & 37 & $1623[498,3304]$ & $6510[1717,14670]$ & $3447[499,6151]$ & $2198[295,4766]$ \\
\hline $\mathrm{B}+$ & Non-I carriers & 3 & $257^{*}, 441^{*}, 801$ & $1638^{*}, 2450,3873$ & $23^{*}, 123^{*}, 145^{*}$ & $43^{*}, 274^{*}, 285^{*}$ \\
\hline BB & Mixed & 11 & $1824[431,3181]$ & $4581[1573,8723]$ & $1540[211,3506]$ & $1329[470,2449]$ \\
\hline $\mathrm{BB}(\mathrm{A})$ & Mixed & 1 & 425 & 3270 & 489 & 603 \\
\hline
\end{tabular}

The mean of the amino acid levels for each group is indicated, with the exception of categories with less than four patients, where individual data are shown. When applicable, the 5th and 95th centile limits are shown in square brackets.

*Data below the 5th centile of values in individuals BB with type non-I cystinuria.

†A sister of this patient has the same genotype and she is in dialysis, and therefore urine amino acid levels are not available. Genotypes are as described in the legend to table 1 .

$n$, number of patients.

identified. The alleles explained were $90.5 \%$ in type I probands, $87.6 \%$ in non-I, $89.3 \%$ in mixed, and $83.6 \%$ in untyped. In 126 probands $(76.8 \%)$ we identified two mutations, in $33(20.1 \%)$ one mutation, and in five $(3.0 \%)$ no mutations. Of the fully explained probands, 56 (34.1\%) and $68(41.5 \%)$ carry two mutations in SLC3AI (probands $\mathrm{AA}$ ) and SLC7A9 (probands BB and $\mathrm{B}+$ ) respectively.

Table 3 describes the type of mutation identified in each allele of the 14 mixed cystinuria probands, which potentially represent 14 phenotype I and 14 phenotype non-I alleles. This table shows that all the possible genotypes in cystinuria are found in mixed families, BB being the most representative genotype.

Data in tables 1 and 3 allow calculation of the number of explained alleles classified by phenotype and genotype (tables 4 and 5): $89.7 \%$ and $88.3 \%$ of the phenotype I and non-I alleles have been explained, respectively. Alleles identified as type A and type B were 125 and 157, respectively. This represents $44.3 \%$ (type A) and $55.7 \%$ (type B) of the alleles identified.
A

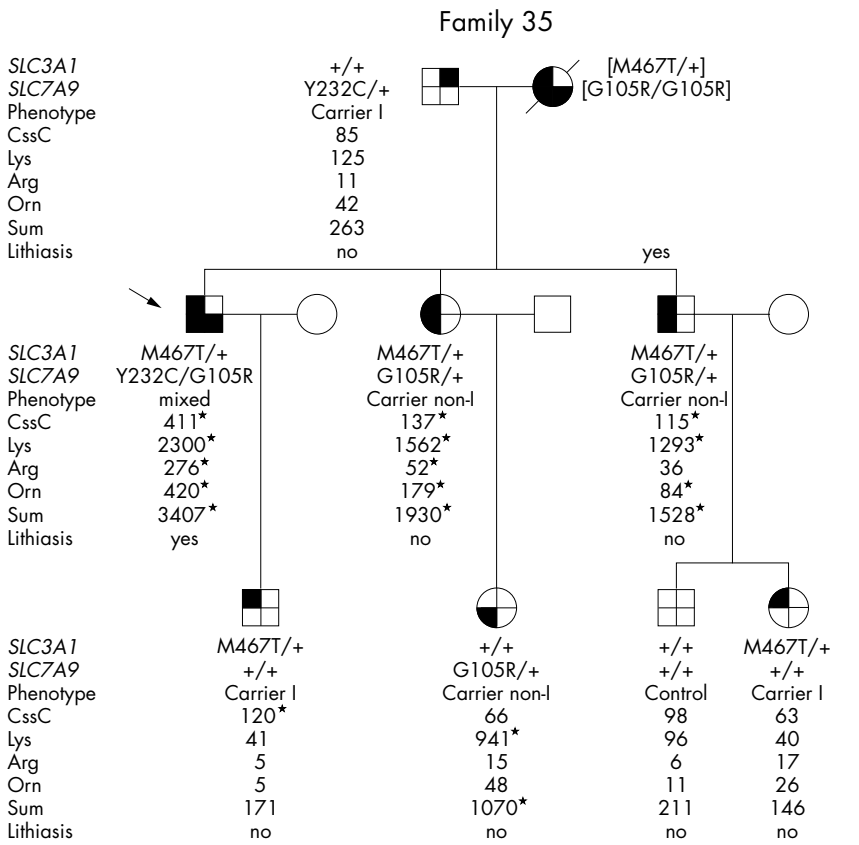

B

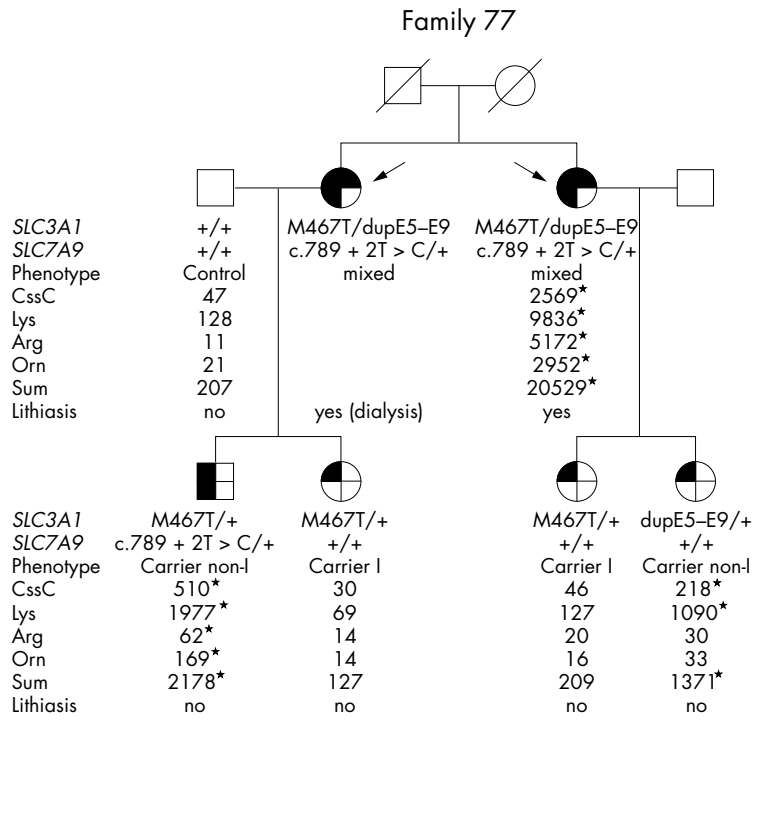

Figure 2 Pedigrees of families with patients that carry mutations in SLC3A1 and SLC7A9. (A) Pedigree of patient BB(A) (family 35). The probands (arrow) have two mutated alleles in SLC7A9 (G105R/Y232C) (type B mutations) and one in SLC3A1 (M467T/+) (type A mutation), and present cystine calculi (lithiasis). Double heterozygotes carrying G105R/+ and M467T/+ had greater amino acid excretion in the urine than single carriers (G105R/+ or $M 467 T /+)$, indicating an impact of digenic inheritance on the urine phenotype. (B) Pedigree of patients $A A(B)$ (family 77). The two patients (arrows) within the family carry two mutated alleles in SLC3A1 (M467T/dupE5-E9) (type A mutations) and one mutation in SLC7A9 (c.789+2T $\rightarrow$ C) (type B mutation) and have cystine calculi (lithiasis). One of the patients is on dialysis as indicated. The other had amino acid excretion values in urine that were above the 89th centile values in patients AA. Again, this indicates that digenic inheritance contributes to the urine phenotype. None of the double carriers in either family had lithiasis. Urine amino acid excretion values for cystine (CssC), lysine (Lys), arginine (Arg), ornithine (Orn), and the sum of the four amino acids are expressed in $\mu \mathrm{mol} / \mathrm{g}$ creatinine. To facilitate interpretation, symbols are divided in four sectors. The upper and lower ones represent SLC3A1 and SLC7A9 alleles respectively. When mutated the sectors are black. ${ }^{*}$ Values above the 95th centile of corresponding amino acid urine values in controls (table 6). 


\section{Genotype-phenotype correlation}

Most type A alleles segregate with cystinuria type I, but type A mutations explained phenotype non-I in obligate heterozygotes in three mixed cystinuria families (tables 1 and 3). To our knowledge this is the first description of SLC3Al mutations with phenotype non-I in heterozygotes. Type B alleles segregated mainly with phenotype non-I (tables 1 and 3). However, in agreement with previous reports, ${ }^{24}{ }^{28}$ SLC7A9 mutations also segregated with phenotype I in heterozygotes. Thus one type I proband carries two type B mutations (BB), and two other type I probands carry one type B mutation (B?) (table 1). Moreover, the phenotype I allele in eight mixed cystinuria probands was explained by type $\mathrm{B}$ mutations (seven $\mathrm{BB}$ and one $\mathrm{BB}(\mathrm{A})$ probands; table 3 ).

SLC3A1 dupE5-E9 show phenotype non-I in most of the heterozygotes

Recently, Schmidt et $a l^{27}$ described a cystinuria specific SLC3A1 rearrangement (c. $(891+1524$ 1618-1600)dup; that is, duplication of exons 5 to 9; dupE5-E9) that results in the in frame duplication of amino acid residues E298 to D539 of the rBAT protein (p.E298_D539dup) as demonstrated by our own RNA studies (not shown) and by Schmidt et al. ${ }^{27}$ Five probands of the ICC database carry this duplication. Four are compound heterozygotes with SLC3A1 mutations (M467T, Spanish family 79; R452W, Spanish family 14; c.765+lG $\rightarrow$ T; Spanish family 92; c.1749delA, Belgian family 106). Two patients in the fifth family (Italian family 77) are compound heterozygotes with SLC3A1 mutations dupE5-E9 and M467T, and also carry the $S L C 7 A 9$ mutation c. $789+2 \mathrm{~T} \rightarrow \mathrm{C}$ in one allele (fig 2B). Amino acid levels in urine for six single dupE5-E9 carriers of families were available (table 6). Interestingly, four of these carriers (F14-C119, F77-SR, F79-A145, and F79A148) showed excretion of cystine and dibasic amino acids within the range of phenotype non-I heterozygotes. In contrast, carrier F106-D18 showed amino acid levels in urine within the control range like most of SLC3Al heterozygotes. Cystine in urine was not analysed in the other carrier in this family but the urine excretion of the other amino acids was within the control range, indicating phenotype I. To our knowledge dupE5-E9 is the first SLC3AI mutation that shows phenotype non-I in heterozygotes.

\section{SLC7A9 mutations that show phenotype I in heterozygotes}

SLC7A9 mutations with phenotype I in heterozygotes are shown in table 7. A182T, G105R, V170M, and c.614dupA are common SLC7A9 mutations (table $3 \mathrm{~s}$ in Supplementary Material). Six of the 11 Al82T carriers showed phenotype I as the average urine levels of cystine, lysine, and the sum of the four amino acids were below the fifth centile of values in heterozygotes $\mathrm{B}+$ with phenotype non-I (table 7). In contrast, the other five Al82T carriers had amino acid levels in the urine above the 95th centile in controls (phenotype non-I) and within the range of values for $\mathrm{B}+$ heterozygotes with phenotype non-I. The proportion of heterozygotes with phenotype I carrying the other common SLC7A9 mutations was variable: T123M (two of four), V170M (four of 16), c.614dupA (one of 19), and G105R (one of 32). In contrast, carriers of the common and severe mutation $\mathrm{R} 333 \mathrm{~W}^{21}$ showed phenotype non-I in all cases. Moreover we describe carriers of six uncommon SLC7A9 mutations that also show phenotype I (G63R, Al26T, G195R, Y232C, and W69X) (table 7). Interestingly, in some of the SLC7A9 heterozygotes with phenotype I, urine levels of cystine but not of dibasic amino acids were above than 95th centile of control values and within the lower range of values of $\mathrm{B}+$ heterozygotes (phenotype non-I). All phenotype I alleles with common or uncommon SLC7A9 mutations belong to mixed (and untyped) families except for family F112, which transmit type I cystinuria (the proband is a G105R/T123M compound heterozygote).

\section{Urine amino acid excretion in patients with cystinuria classified by genotype and phenotype}

Table 8 shows the excretion of cystine and dibasic amino acids in urine of patients in relation to their allele genotype (A or B) and their cystinuria type. Three groups of patients were numerous enough for statistical comparisons: patients AA with type I $(n=34)$, patients $B B$ with type non-I $(\mathrm{n}=37)$, and patients $\mathrm{BB}$ with mixed type $(\mathrm{n}=11)$. The average urine levels of cystine and the three dibasic amino acids, as well as the 5 th and 95 th centile of these values, were very similar for patients AA with type I and BB with type non-I. This is shown graphically for the sum of the urine excretion of the four amino acids in fig 1 . The average and the 95th centile of urine excretion of lysine, arginine, and ornithine, and the sum of the four amino acids were lower in patients $\mathrm{BB}$ with mixed type than in patients $\mathrm{AA}$ with type I and patients BB with type non-I. Similarly, patients BB with type I cystinuria showed urine excretion values for dibasic amino acids within the lower limit of excretion values in patients BB with type non-I and AA with type I. In contrast, urine cystine levels were very similar in all these groups. This probably reflects the fact that most of the cystinuria patients reached the limit of solubility of cystine in urine $(300 \mathrm{mg} / \mathrm{l}$ or $1.2 \mathrm{mM}),{ }^{31}$ and this resulted in an underestimation of this amino acid in the urine when the sample was not previously diluted to dissolve cystine microcrystals. Indeed, the 95th centile of cystine levels in urine in these four groups of patients (up to $\sim 3400 \mu \mathrm{mol} / \mathrm{g}$ creatinine) represents $3.4 \mathrm{mM}$, assuming $1 \mathrm{~g}$ creatinine/litre of urine.

Three patients with cystine urolithiasis were classified as heterozygotes for SLC7A9 mutations $(\mathrm{B}+)$ on the basis of their urine amino acid concentrations (table 8, fig 1 ), which were similar to that of the parent transmitting the mutation (data not shown) and within the range of excretion of heterozygotes $\mathrm{B}+$ with phenotype non-I (table 7 ). Moreover, these three patients excreted less arginine and ornithine than the fifth centile of patients BB with mixed cystinuria (table 8).

Only three AA patients with mixed cystinuria were identified in the ICC database (table 8, fig 1). The two patients with higher amino acid excretion values are siblings (family 14) and compound heterozygotes (dupE5-E9/ R452W), and one of them had very substantial aminoaciduria. The expected severe defect of mutations R452W (that is, a non-conservative amino acid substitution) and dupE5-E9 (the only SLC3A1 mutation that associated with phenotype non-I in heterozygotes) might contribute to the severe urine phenotype in this patient. The third patient (family 79), who had the lowest amino acid excretion values in urine (within the lower range of patients AA (type I)), is a compound heterozygote (dupE5-E9/M467T). Patient homozygotes for M467T or compound heterozygotes carrying M467T showed lower amino acid excretion values in urine (mean (SEM), $\mu \mathrm{mol} / \mathrm{g}$ creatinine, $\mathrm{n}=20$ : 1414 (136) for cystine, 5753 (669) for lysine, 1718 (404) for arginine, 1227 (160) for ornithine, and 9859 (1222) for the sum of the four amino acids) than AA patients without this mutation $(\mathrm{n}=33: 2376$ (291) for cystine, 9173 (835) for lysine, 3655 (378) for arginine, 3526 (505) for ornithine, and 18730 (1517) for the sum of the four amino acids). Indeed, three patients homozygous for M467T had amino acid concentrations in urine (sum of the four amino acids: 5613, 6433, and $8113 \mu \mathrm{mol} / \mathrm{g}$ creatinine ${ }^{6}$ ) that were among the lowest in patients AA. Thus the mild phenotype of M467T might contribute to the low amino acid excretion values in the compound heterozygote dupE5-E9/ M467T. 


\section{Digenic inheritance causing a partial phenotype in two cystinuria families}

Patient $\mathrm{BB}(\mathrm{A})$ (family 35; fig $2 \mathrm{~A}$ ) is a compound heterozygote of SLC7A9 mutations (Y232C/G105R) that also carries the SLC3A1 mutation M467T. Mutations Y232C and M467T showed phenotype I, whereas G105R showed phenotype non-I in the heterozygotes of this family. Patient BB(A) was then classified as presenting mixed cystinuria. This patient had very low urine amino acid levels, which were similar to the fifth centile of these values in patients BB (type non-I). Two members of this family are double carriers (AB) (G105R/ + for SLC7A9 and M467T/+ for SLC3A1). Digenic cystinuria without urolithiasis is suggested in these two double carriers, as they had higher urinary excretion values than the single heterozygotes (G105R/+ or M467T/+) within the family. Patient $\mathrm{AA}(\mathrm{B})$ (family 77; figs $\mathrm{l}$ and $2 \mathrm{~B}$ ) had very high amino acid concentrations in the urine and at the time of this study her sister was on dialysis. Both carry SLC3A1 mutations dupE5-E9 and M467T and the SLC7A9 mutation c.789+2T $\rightarrow$ C. M467T showed phenotype I, whereas dupE5E9 showed phenotype non-I in the heterozygotes identified in this family. Patients $\mathrm{AA}(\mathrm{B})$ were then classified as having mixed cystinuria. The type B mutation seems to contribute to the severe phenotype in these patients. Thus one of these patients (M467T/dupE5-E9 and c.789+2T $\rightarrow \mathrm{C} /+$ ) excreted larger amounts of amino acids than patient M467T/dupE5E9 (family 79) (compare patient $\mathrm{AA}(\mathrm{B})$ and patient $\mathrm{AA}$ (mixed) with the lowest aminoaciduria in table 8 and fig 1 ). In contrast, the mild mutation M467T did not seem to aggravate the urine phenotype of the double carrier in family 77 (M467T/+ and c.2789+2T $\rightarrow \mathrm{C} /+$ ). Thus the aminoaciduria in this double carrier was lower than that of two single c. $782+2 \mathrm{~T} \rightarrow \mathrm{C}$ heterozygotes (family 58), which had the greatest aminoaciduria (the sum of the urine levels of the four amino acids was 8112 and $8307 \mathrm{mmol} / \mathrm{g}$ creatinine) among the heterozygotes $\mathrm{B}+$ in our database.

\section{DISCUSSION}

We describe 40 new cystinuria mutations (24 in SLC3Al and 16 in SLC7A9) which bring the total number of cystinuria specific mutations identified to 103 in SLC3Al and 66 in SLC7A9. The mutations include missense, nonsense, splicing defects, frameshift, deletions and insertions of a single amino acid residue, and large rearrangements. To our knowledge, the present study represents the largest percentage of cystinuria alleles explained in any large cohort of patients reported $\left(86.8 \% ; 282\right.$ of 325 alleles). In a recent study, ${ }^{27}$ only $64.7 \%$ of the alleles were explained ( 75 of 116 alleles). In the ICC database, the coverage of identified alleles is similar for probands with different cystinuria types (on average $89.3 \%$ ). The percentage of explained alleles in untyped patients was lower $(83.6 \%)$, which might be attributed to the presence of SLC7A9 carriers with cystine urolithiasis.

The greater number of characterised alleles allows a general summary of the cystinuria mutations in the ICC database, which includes patients of mainly Italian, Spanish, or Libyan-Jewish origin. Type A (SLC3A1) and type B (SLC7A9) mutations accounted for $44.3 \%$ and $55.7 \%$ of the explained alleles, respectively. To our knowledge, these are the first relative frequencies of type A and type B alleles to be reported, but they must be viewed with caution. The ICC database is not a registry, as we did not collect all possible cases. ${ }^{28}$ The ICC was very active in collecting phenotype non-I cystinuria cases in order to identify the SLC7A9 gene, ${ }^{210}{ }^{11}$ and the prevalence of type B mutations might be overestimated. M467T and G105R were the most common type A and type B mutations $(26.4 \%$ and $27.4 \%$ of each type of alleles, respectively). This is consistent with reports on other smaller cohorts of patients with cystinuria. ${ }^{1623} 25$ The five most common type A and type B mutations accounted for $44.8 \%$ and $63.1 \%$ of the identified alleles of each type (A or B), respectively. Moreover, 55 SLC3A1 and 45 SLC7A9 mutations covered the 125 type A and the 157 type B explained alleles, respectively, showing that $S L C 3 A I$ has greater genetic heterogeneity than SLC7A9 in the ICC database.

The present search for mutations was very careful (SSCP, DHPLC, direct sequencing, and specific search for large rearrangements of SLC3A1 and SLC7A9) and covered the whole coding region and all intron/exon boundaries. The unexplained cystinuria alleles $(13.2 \%)$ may be the result of mutations in intronic or promoter regions not yet identified in the two known cystinuria genes or they may reflect unidentified genes. Also, SLC3A1 or SLC7A9 polymorphisms in combination with cystinuria specific mutations might result in full blown cystinuria, for the following reasons.

First, the promoter region of these genes was not analysed in this study, but a small contribution of mutations in these regions is expected. Indeed, two cystinuria specific sequence variants in the promoter region of SLC3Al have been reported, ${ }^{19}$ but functional studies should be done to confirm these mutations.

Second, intronic mutations affecting sequences other than the splice-site consensus ones could explain these alleles, but RNA studies would be necessary to assess this.

Third, a third cystinuria gene cannot be discounted but it would be relegated to a very small proportion of patients (no mutations were found in any of the two cystinuria genes in only $3 \%$ of the probands), and seems improbable. Coimmunoprecipitation studies and the SLC7A9 KO model showed that the protein products of SLC3Al (rBAT) and SLC7A9 $\left(\mathrm{b}^{0,+} \mathrm{AT}\right)$ heterodimerise in mouse kidney brush border membranes, but a significant part of rBAT heterodimerises with an unknown light subunit $(X) .{ }^{12}{ }^{32}$ This may also be true in human kidney brush borders. ${ }^{12}$ Therefore, the gene coding for $\mathrm{X}$ could be a candidate for cystinuria. However, the similar hyperexcretion of amino acids detected in urine of patients $\mathrm{AA}$ and $\mathrm{BB}$ does not support this hypothesis. If $X$ were coded by a cystinuria gene one would expect a greater degree of aminoaciduria in patients AA than in patients $\mathrm{BB}-\mathrm{b}^{0,+} \mathrm{AT}$ mutations would affect system $\mathrm{b}^{0,+}$ only, whereas rBAT mutations would affect system $b^{0,+}$ and the transport activity of the $\mathrm{rBAT} / \mathrm{X}$ heteromeric complex.

Finally, SLC3A1 or SLC7A9 polymorphisms in combination with cystinuria specific mutations might result in full blown cystinuria, as has been suggested..$^{33}$ Cystinuria association and functional analysis of these polymorphisms are required to demonstrate their contribution to the disease.

Some heterozygotes for the SLC3AI mutation dupE5-E9which results in the duplication of the rBAT fragment E298D539-presented with phenotype non-I (table 6). All other SLC3Al mutations, including very severe ones (for example, c.163delC which produces a frameshift with an early stop codon, eliminating the transmembrane and the extracellular domains of rBAT (p.Q55fsX51); or c.431_2055del, which eliminates $80 \%$ of the rBAT residues towards the C-terminus (p.G144_C685del)) showed phenotype I. ${ }^{6} 18222534$ This indicates that mutation dupE5-E9 has a dominant negative effect on the $\mathrm{rBAT} / \mathrm{b}^{0,+} \mathrm{AT}$ heteromeric complex.

Because $14 \%$ of SLC7A9 heterozygotes showed phenotype I we proposed a classification of cystinuria on the basis of genotype rather than phenotype. ${ }^{28}$ Rozen and coworkers identified two type I heterozygotes carrying the SLC7A9 mutations I44T and P261L, respectively. ${ }^{24}$ Here we report 10 more of these SLC7A9 mutations. Four showed phenotype I in several carriers (A182T, T123M, G63R, and V170M). Mutations A182T and T123M affect non-conserved amino acid residues in the family of the light subunits of HATs. Moreover, Al82T is a mild mutation with aberrant trafficking 
to the plasma membrane ${ }^{35}$ and substantial residual transport activity $(60 \%){ }^{21}$ Similarly, A126T and P261L, with a single type I carrier identified, also involve non-conserved amino acid residues. Interestingly, patients BB with mixed or type I cystinuria (that is, with type B heterozygotes with phenotype I in their families) also presented with a mild urine phenotype (table 8 and fig 1). This agrees with the mild urine phenotype reported for patients with mixed cystinuria. ${ }^{36}$ Seven of the 11 patients BB (mixed) and the patient $\mathrm{BB}$ (type I) carry Al82T or T123M. The mild amino acid transport defect of these mutations could be the underlying cause of the mild urine phenotype of these patients. In contrast, other mutations with phenotype I in heterozygotes (I44T, G63R, G105R, V170M, G195R, and Y232C) involved fully conserved amino acid residues or resulted in large protein changes (W69X, with $\mathrm{b}^{0,+} \mathrm{AT}$ truncated after the first transmembrane domain; c.614dupA, a mutation shown by mRNA studies to result in skipping of exons 5 and 6 (r.479_709del), producing a frameshift at residue 160 (p.L160fsX1); data not shown). Moreover, G105R and Vl70M have little amino acid transport function. ${ }^{21}$ Interestingly, a very small proportion of heterozygotes who carry severe and common mutations like c.614dupA (one of 19 carriers) and G105R (one of 32 carriers) had phenotype I, but one quarter of the VI70M heterozygotes manifested phenotype I (all from a Libyan Jewish origin). This indicates that, in addition to the residual functional activity of $b^{0,+} A T$ mutants, other factors (environmental or genetic) contribute to the urine phenotype of carriers of SLC7A9 mutations.

Only three patients in the ICC database are double compound heterozygotes with mutations in both genes (two patients with mutations M467T and dupE5-E9 (AA), and c.789+2T $\rightarrow$ C (B), and one patient with mutations Y232C and G105R (BB), and M467T (A)). One patient AA(B) has previously been reported but with no description of the associated urine phenotype. ${ }^{37}$ The degree of aminoaciduria of these type of patient and their relatives in the ICC database indicates that digenic inheritance in cystinuria has only a partial effect on the phenotype, restricted to a variable impact on the aminoaciduria, for the following reasons.

First, in family 77, the severe aminoaciduria in one of the patients $\mathrm{AA}(\mathrm{B})$ indicates that the type $\mathrm{B}$ mutation c. $789+2 \mathrm{~T} \rightarrow \mathrm{C}$, associated with high aminoaciduria in heterozygotes, contributes to the urine phenotype; no information is available from the other patient $\mathrm{AA}(\mathrm{B})$ as she is on dialysis.

Second, in family 35, the mild aminoaciduria of patient $\mathrm{BB}(\mathrm{A})$ indicates that M467T, associated with mild aminoaciduria in homozygotes and compound heterozygotes, does not contribute to the urine phenotype in the patient, but two double compound heterozygotes in this family (M467T/+, G105R/+; that is, $\mathrm{AB}$ ) showed greater aminoaciduria than the single heterozygotes within the family, suggesting a contribution of both mutations to the urine phenotype.

Third, none of the individuals $\mathrm{AB}$ had cystine urolithiasis. Given that almost $90 \%$ of the alleles of the ICC cohort of patients have been identified, and that the frequency of type $\mathrm{A}$ and $\mathrm{B}$ alleles is similar in this cohort, if digenic inheritance was the rule in cystinuria, we would expect $25 \%$ AA patients, $25 \% \mathrm{BB}$ patients, and $50 \% \mathrm{AB}$ patients. Furthermore, the few $\mathrm{AB}$ individuals identified did not have cystine urolithiasis. This indicates that digenic inheritance, affecting the phenotype, is an exception in cystinuria. However, we cannot discard the possibility that some combinations of mutations $\mathrm{A}$ and $\mathrm{B}$ produce enough cystine hyperexcretion to cause urolithiasis. In this regard, the urolithiasis activity of individuals $\mathrm{B} /+$, with a low penetrance for cystine urolithiasis (three of 192 genotyped patients; 1.7\%), might be aggravated by the addition of the effect of one type A allele.
A working hypothesis on the biogenesis of the $\mathrm{rBAT} / \mathrm{b}^{0,+} \mathrm{AT}$ heterodimer and the urine phenotypes in cystinuria may explain the apparent lack of full digenic inheritance in cystinuria. In the first place, the rBAT protein is produced in excess in the kidney, and therefore an rBAT mutation in heterozygosis (for example, the mouse cystinuria model with the $S L C 3 A 1$ mutation D140G ${ }^{38}$ and all human cystinuria rBAT mutations with the exception of dupE5-E9) does not lead to hyperexcretion of amino acids (phenotype I). Secondly; $\mathrm{b}^{0,+} \mathrm{AT}$ controls the expression of the functional rBAT/ $/ \mathrm{b}^{0,+} \mathrm{AT}$ heterodimeric complex-interaction with $\mathrm{b}^{0,+} \mathrm{AT}$ stabilises rBAT and the excess of rBAT is degraded, as shown in transfected cells. ${ }^{35}{ }^{39}$ As a result, a half dose of $b^{0,+} \mathrm{AT}$ (heterozygotes of severe human SLC7A9 mutations or of the SLC7A9 knockout mice ${ }^{32}$ ) results in a significant decrease in the expression of $\mathrm{rBAT} / \mathrm{b}^{0,+} \mathrm{AT}$ heterodimer complex (system $\left.\mathrm{b}^{0,+}\right)$, which causes hyperexcretion of cystine and dibasic amino acids. In this scenario, the lack of a full phenotype because of digenic inheritance indicates that in double heterozygotes $(\mathrm{AB})$, the mutated $\mathrm{rBAT}$, with trafficking defects, $^{18} 4041$ does not interact with, or does not compromise, the heterodimerisation and trafficking to the plasma membrane of the half dose of wild type $\mathrm{b}^{0,+} \mathrm{AT}$ with the half dose of wild type rBAT. Thus $A B$ individuals behave as $B$ heterozygotes with a variable degree of aminoaciduria, which could be greater than that of the single heterozygotes within the family, depending on the particular combination of mutations. We are currently studying the hypothesis that the phenotype non-I associated to the SLC3Al mutation dupE5E9 reflects heterodimerisation with $\mathrm{b}^{0,+} \mathrm{AT}$, which results in a non-active heteromeric complex.

\section{ACKNOWLEDGEMENTS}

We thank the families who participated in this study. We also thank L Sánchez for technical help and Tanya Yates for editorial help. This work was supported in part by the Spanish Ministry of Science and Technology (PM99-0172-CO-01/02 and SAF2003-08940-01/02), BIOMED (BMH4 CT98-3514), the Spanish Institut de Salud Carlos III (networks G03/054, C03/07, and C03/08), the Generalitat de Catalunya (2001 SGR00399; 2001 SGR00118), and the Marató de TV3 (98130) to VN and MP, by the Comissionat per a Universitats i Recerca to MP, and by the Ministero Italiano della Salute (Ricerca Corrente 2001) to LZ. MF-L was a recipient of a predoctoral fellowship from the Comissió Interdepartamental de Recerca i Innovació Tecnològica from the Generalitat de Catalunya. MJ-V was supported by the BIOMED BMH4 CT98-3514 and EUGINDAT (LSHM-CT-2003-502852).

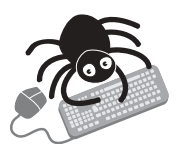

Supplementary material: Supplementary figures and tables can be accessed at the JMG website (www.jmg.com/supplemental)

\section{Authors' affiliations}

M Font-Llitiós, M Jiménez-Vidal, V Nunes, Centre of Medical and Molecular Genetics (IRO), Hospital Duran i Reynals, Barcelona, Spain M Jiménez-Vidal, M Palacín, Department of Biochemistry and Molecular Biology, Faculty of Biology, University of Barcelona

L Bisceglia, M D Perna, L Zelante, Medical Genetics Service, IRCCSHospital "CSS", San Giovanni Rotondo, Italy

L de Sanctis, Department of Paediatrics, Regina Margherita Children's Hospital, University of Torino, Italy

F Rousaud, Urology Service Fundació Puigvert, Barcelona

Competing interests: none declared

\section{REFERENCES}

1 Palacín M, Goodyer P, Nunes V, Gasparini P. Cystinuria. In: Scriver CR, Beaudet AL, Sly WS et al, eds. In: The metabolic and molecular bases of inherited disease, 8th ed, vol III. New York: McGraw-Hill, 2001:4909-32.

2 Feliubadalo L, Font M, Purroy J, Rousaud F, Estivill X, Nunes V, Golomb E, Centola M, Aksentijevich I, Kreiss Y, Goldman B, Pras M, Kastner DL, Pras E, 
Gasparini P, Bisceglia L, Beccia E, Gallucci M, de Sanctis L, Ponzone A, Rizzoni GF, Zelante L, Bassi MT, George AL, Palacin M, et al. Non-type I cystinuria caused by mutations in SLC7A9, encoding a subunit (bo, +AT) of rBAT. International Cystinuria Consortium. Nat Genet 1999;23:52-7.

3 Goodyer PR, Clow C, Reade T, Girardin C. Prospective analysis and classification of patients with cystinuria identified in a newborn screening program. J Pediatr 1993;122:568-72.

4 Bertran J, Werner A, Moore ML, Stange G, Markovich D, Biber J, Testar X Zorzano A, Palacin M, Murer $\mathrm{H}$. Expression cloning of a cDNA from rabbi kidney cortex that induces a single transport system for cystine and dibasic and neutral amino acids. Proc Natl Acad Sci USA 1992;89:5601-5.

5 Lee WS, Wells RG, Sabbag RV, Mohandas TK, Hediger MA. Cloning and chromosomal localization of a human kidney cDNA involved in cystine, dibasic, and neutral amino acid transport. J Clin Invest 1993;91:1959-63.

6 Calonge MJ, Gasparini P, Chillaron J, Chillon M, Gallucci M, Rousaud F, Zelante L, Testar X, Dallapiccola B, Di Silverio F, Barcelo P, Estivill X, Zorzano A, Nunes V, Palacín M. Cystinuria caused by mutations in rBAT, a gene involved in the transport of cystine. Nat Genet 1994;6:420-5.

7 Calonge MJ, Nadal M, Calvano S, Testar X, Zelante L, Zorzano A, Estivill X, Gasparini P, Palain M, Nunes V. Assignment of the gene responsible for cystinuria (rBAT) and of markers D2S119 and D2S177 to 2p16 by fluorescence in situ hybridization. Hum Genet 1995;95:633-6.

8 Gasparini P, Calonge MJ, Bisceglia L, Purroy J, Dianzani I, Notarangelo A, Rousaud F, Gallucci M, Testar X, Ponzone A, et al. Molecular genetics of cystinuria: identification of four new mutations and seven polymorphisms, and evidence for genetic heterogeneity. Am J Hum Genet 1995;57:781-8.

9 Wartenfeld R, Golomb E, Katz G, Bale SJ, Goldman B, Pras M, Kastner DL, Pras $E$. Molecular analysis of cystinuria in Libyan Jews: exclusion of the SLC3A1 gene and mapping of a new locus on 19q. Am J Hum Genet 1997;60:617-24.

10 Bisceglia L, Calonge MJ, Totaro A, Feliubadalo L, Melchionda S, Garcia J, Testar X, Gallucci M, Ponzone A, Zelante L, Zorzano A, Estivill X, Gasparini P Nunes $V$, Palacin $M$. Localization, by linkage analysis, of the cystinuria type III gene to chromosome 19q13.1. Am J Hum Genet 1997;60:611-16.

11 Feliubadalo L, Bisceglia L, Font M, Dello Strologo L, Beccia E, ArslanKirchner M, Steinmann B, Zelante L, Estivill X, Zorzano A, Palacín M, Gasparini $P$, Nunes $V$. Recombinant families locate the gene for non-type I cystinuria between markers C13 and D19S587 on chromosome 19q13.1. Genomics 1999;60:362-5.

12 Fernandez E, Carrascal M, Rousaud F, Abian J, Zorzano A, Palacin M, Chillaron J. rBAT-b $(0,+)$ AT heterodimer is the main apical reabsorption system for cystine in the kidney. Am J Physiol Renal Physiol 2002;283:F540-8.

13 Chillaron J, Roca R, Valencia A, Zorzano A, Palacin M. Heteromeric amino acid transporters: biochemistry, genetics, and physiology. Am J Physiol Renal Physiol 2001;281(6):F995-1018.

14 Bisceglia L, Calonge MJ, Dello Strologo L, Rizzoni G, de Sanctis L, Gallucci M, Beccia E, Testar X, Zorzano A, Estivill X, Zelante L, Palacin M, Gasparini P, Nunes $V$. Molecular analysis of the cystinuria disease gene: identification of four new mutations, one large deletion, and one polymorphism. Hum Genet 1996;98:447-51.

15 Pras E, Golomb E, Drake C, Aksentijevich I, Katz G, Kastner DL. A splicing mutation $(891+4 \mathrm{~A} \rightarrow \mathrm{G})$ in SLC3A1 leads to exon 4 skipping and causes cystinuria in a Moslem Arab family. Hum Mutat 1998;(suppl 1):S28-30.

16 Gitomer WL, Reed BY, Ruml LA, Sakhaee K, Pak CY. Mutations in the genomic deoxyribonucleic acid for SLC3A1 in patients with cystinuria. J Clin Endocrinol Metab 1998:83:3688-94.

17 Gitomer WL, Reed BY, Ruml LA, Pak CY. 335-base deletion in the mRNA coding for a dibasic amino acid transporter-like protein (SLC3A1) isolated from a patient with cystinuria. Hum Mutat 1998;(suppl 1):S69-71

18 Saadi I, Chen XZ, Hediger M, Ong P, Pereira P, Goodyer P, Rozen R. Molecular genetics of cystinuria: mutation analysis of SLC3A1 and evidence for another gene in type I (silent) phenotype. Kidney Int 1998;54:48-55.

19 Boutros M, Ong P, Saadi I, Hiou-Tim F, Vicanek C, Rozen R, Goodyer P. The human rBAT promoter mutations in cystinuria [abstract]. Am J Hum Genet 1999;65(suppl):A94.

20 Purroy J, Bisceglia L, Jaeken J, Gasparini P, Palacin M, Nunes V. Detection of two novel large deletions in SLC3A1 by semi-quantitative fluorescent multiplex PCR. Hum Mutat 2000;15:373-9.

21 Font M, Feliubadalo L, Estivill X, Nunes V, Golomb E, Kreiss Y, Pras E, Bisceglia L, d'Adamo AP, Zelante L, Gasparini P, Bassi MT, George AL, Manzoni M, Riboni M, Ballabio A, Borsani G, Reig N, Fernandez E, Zorzano A, Bertran J, Palacín M. Functional analysis of mutations in SLC7A9, and genotype-phenotype correlation in non-Type I cystinuria. Hum Mol Genet 2001; 10:305-16.

22 Bisceglia L, Purroy J, Jimenez-Vidal M, d'Adamo AP, Rousaud F, Beccia E, Penza R, Rizzoni G, Gallucci M, Palacín M, Gasparini P, Nunes V, Zelante L. Cystinuria type I: identification of eight new mutations in SLC3A1. Kidney Int 2001;59:1250-6.

23 Harnevik L, Fjellstedt E, Molbaek A, Tiselius HG, Denneberg T, Soderkvist P. Identification of 12 novel mutations in the SLC3A1 gene in Swedish cystinuria patients. Hum Mutat 2001;18:516-25.

24 Leclerc D, Boutros M, Suh D, Wu Q, Palacin M, Ellis JR, Goodyer P, Rozen R. SLC7A9 mutations in all three cystinuria subtypes. Kidney Int 2002;62:1550-9

25 Botzenhart E, Vester U, Schmidt C, Hesse A, Halber M, Wagner C, Lang F, Hoyer P, Zerres K, Eggermann T. Cystinuria in children: distribution and frequencies of mutations in the SLC3A1 and SLC7A9 genes. Kidney Int 2002;62: 1136-42.

26 Schmidt C, Albers A, Tomiuk J, Eggermann K, Wagner C, Capasso G, Lahme S, Hesse A, Lang F, Zerres K, Eggermann T. Analysis of the genes SLC7A9 and SLC3A1 in unclassified cystinurics: mutation detection rates and association between variants in SLC7A9 and the disease. Clin Nephrol 2002; 57:342-8.

27 Schmidt C, Vester U, Wagner CA, Lahme S, Hesse A, Hoyer P, Lang F, Zerres K, Eggermann T. Significant contribution of genomic rearrangements in SLC3A1 and SLC7A9 to the etiology of cystinuria. Kidney Int 2003;64:1564-72

28 Dello Strologo L, Pras E, Pontesilli C, Beccia E, Ricci-Barbini V, de Sanctis L, Ponzone A, Gallucci M, Bisceglia L, Zelante L, Jimenez-Vidal M, Font M, Zorzano A, Rousaud F, Nunes V, Gasparini P, Palacin M, Rizzoni G. Comparison between SLC3A1 and SLC7A9 cystinuria patients and carriers: a need for a new classification. J Am Soc Nephrol 2002;13:2547-53.

29 Turnell DC, Cooper JD. Rapid assay for amino acids in serum or urine by precolumn derivatization and reversed-phase liquid chromatography. Clin Chem 1982;28:527-31

30 Cartegni L, Wang J, Zhu Z, Zhang MQ, Krainer AR. ESEfinder: a web resource to identify exonic splicing enhancers. Nucleic Acids Res 2003;31:3568-71

31 Dahlberg PJ, van den B, Kurtz SB, Wilson DM, Smith LH. Clinical features and management of cystinuria. Mayo Clin Proc 1977;52:533-42.

32 Feliubadalo L, Arbones ML, Manas S, Chillaron J, Visa J, Rodes M, Rousaud F, Zorzano A, Palacin M, Nunes V. Slc7a9-deficient mice develop cystinuria non-I and cystine urolithiasis. Hum Mol Genet 2003;12:2097-108.

33 Schmidt C, Tomiuk J, Botzenhart E, Vester U, Halber M, Hesse A, Wagner C, Lahme S, Lang F, Zerres K, Eggermann T, Bachmann H, Bokenkamp A Fischbach M, Frund S, Pistor KG, Zappel HF. Genetic variations of the SLC7A9 gene: allele distribution of 13 polymorphic sites in German cystinuria patients and controls. Clin Nephrol 2003;59:353-9.

34 Horsford J, Saadi I, Raelson J, Goodyer PR, Rozen R. Molecular genetics of cystinuria in French Canadians: identification of four novel mutations in type I patients. Kidney Int 1996;49:1401-6.

35 Reig N, Chillaron J, Bartoccioni P, Fernandez E, Bendahan A, Zorzano A, Kanner B, Palacin $M$, Bertran J. The light subunit of system $b(0,+)$ is fully functional in the absence of the heavy subunit. Embo J 2002:21:4906-14.

36 Goodyer P, Saadi I, Ong P, Elkas G, Rozen R. Cystinuria subtype and the risk of nephrolithiasis. Kidney Int 1998;54:56-61.

37 Harnevik L, Fjellstedt E, Molbaek A, Denneberg T, Soderkvist P. Mutation analysis of SLC7A9 in cystinuria patients in Sweden. Genet Test 2003;7:13-20.

38 Peters T, Thaete C, Wolf S, Popp A, Sedlmeier R, Grosse J, Nehls MC, Russ A, Schlueter V. A mouse model for cystinuria type I. Hum Mol Genet 2003; 12:2109-20.

39 Bauch C, Verrey F. Apical heterodimeric cystine and cationic amino acid transporter expressed in MDCK cells. Am J Physiol Renal Physiol 2002;283:F181-9.

40 Chillaron J, Estevez R, Samarzija I, Waldegger S, Testar X, Lang F, Zorzano A, Busch A, Palacin M. An intracellular trafficking defect in type I cystinuria rBAT mutants M467T and M467K. J Biol Chem 1997;272:9543-9.

41 Pineda M, Fernandez E, Torrents D, Estevez R, Lopez C, Camps M, Lloberas J, Zorzano A, Palacin M. Identification of a membrane protein, LAT-2, that coexpresses with 4F2 heavy chain, an L-type amino acid transport activity with broad specificity for small and large zwitterionic amino acids. J Biol Chem 1999;274: 19738-44. 